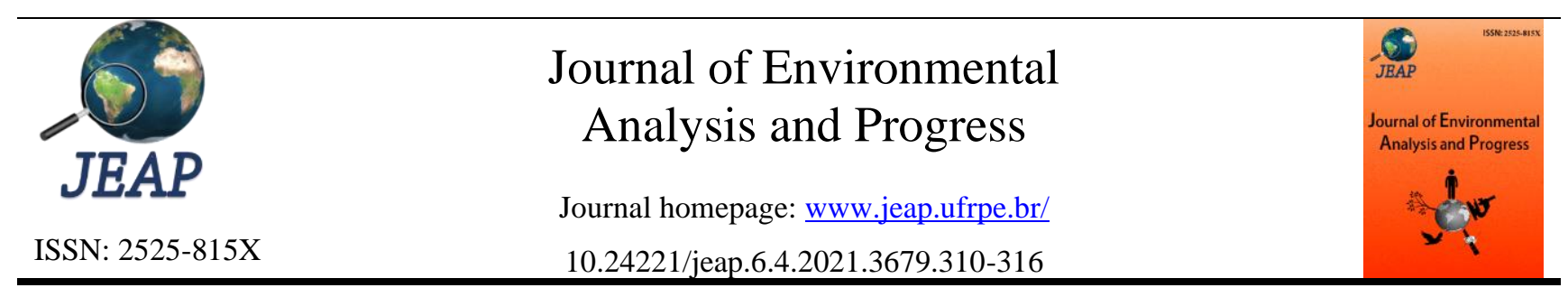

\title{
Morfologia externa de Miconia prasina (Sw.) DC. em estádio inicial de desenvolvimento
}

\section{External morphology of Miconia prasina (Sw.) DC. at an early stadium of development}

\author{
Bárbara Jossany Gomes de Santana ${ }^{\mathrm{a}}$, Joselane Príscila Gomes da Silva ${ }^{\mathrm{b}}$, Luiz Carlos Marangon ${ }^{\mathrm{c}}$ \\ a Universidade Federal Rural de Pernambuco-UFRPE, Graduação em Engenharia Florestal. Rua Dom Manuel de \\ Medeiros, s/n, Dois Irmãos, Recife/PE, Brasil. CEP: 52171-900. E-mail: barbarajossanny@gmail.com. \\ b UFRPE, Pós-Graduação em Ciências Florestais-PPGCF. E-mail: joselane.gomess@ gmail.com. \\ ${ }^{\mathrm{c}}$ UFRPE, Departamento de Ciência Florestal-DCFL. E-mail: luiz.marangon@ufrpe.br.
}

\begin{tabular}{|c|c|}
\hline A R T I C L E I N F O & A B S T R A C T \\
\hline $\begin{array}{l}\text { Recebido } 30 \text { Jun } 2020 \\
\text { Aceito } 27 \text { Set } 2021 \\
\text { Publicado } 12 \text { Out } 2021\end{array}$ & $\begin{array}{l}\text { Studies related to the external morphology of seedlings support different areas, } \\
\text { detaching those of natural regeneration and succession, because of the assist in } \\
\text { species identification. The study aimed to describe the external morphology of } \\
\text { Miconia prasina (Sw.) DC., in an early stage of development. The fruits of Miconia } \\
\text { were collected in a remnant of the Tropical Lowland Rainforest. The material } \\
\text { collected was taken to the Forest Seed Analysis Laboratory (LASF) in the Forest } \\
\text { Science Department (DCFL) of the Rural Federal University of Pernambuco } \\
\text { (UFRPE). The seedlings description was obtained from seeds germinated in an } \\
\text { acrylic box; the substrate used was paper towels. After seed germination and initial } \\
\text { seedling growth, they were transplanted to polyethylene recipients containing soil } \\
\text { and vermiculite. The seedlings were taken to a greenhouse in the Forest Nursery } \\
\text { from DCFL/UFRPE. They were manually watered and observed to describe all the } \\
\text { characteristics of the external morphology. Germination started on the 17th day } \\
\text { after sowing, with the radicle emission. The beginning of cotyledon emission } \\
\text { occurred on the 19th day, with the argument persisting in the apex. On the } 25 \text { th } \\
\text { day, there was a total exposure of cotyledons, foliaceous, of green color. The } \\
\text { germination was determined to be of the epigeal phanerocotiledonar type. The first } \\
\text { eophyll appeared } 35 \text { days after sowing, presented as simple, pubescent, smooth } \\
\text { edge, petiolate, and opposite phyllotaxis. The species expressed similar } \\
\text { characteristics of the adult individual but with a slight polymorphism, making } \\
\text { identification until the seedling stage difficult. }\end{array}$ \\
\hline
\end{tabular}

Keywords: Cotyledon, germination, seedling.

\section{R E S U M O}

Estudos relacionados à morfologia externa de plântulas subsidiam diferentes áreas do conhecimento, destacando aqueles sobre regeneração e sucessão natural, por auxiliar na identificação das espécies. O estudo objetivou descrever a morfologia externa de Miconia prasina (Sw.) DC., em estádio inicial de desenvolvimento. Os frutos foram coletados em um remanescente de Floresta Ombrófila Densa das Terras Baixas. O material retirado dos coletores foi levado para o Laboratório de Análise de Sementes Florestais (LASF), no Departamento de Ciência Florestal (DCFL) da Universidade Federal Rural de Pernambuco (UFRPE). Para a descrição das plântulas, as sementes foram semeadas em caixa gerbox, utilizando papel toalha como substrato. Após a germinação das sementes e crescimento inicial das plântulas, estas foram transplantadas para recipientes de polietileno contendo solo comum e vermiculita. Em seguida, foram levadas para casa de vegetação no viveiro florestal-DCFL/UFRPE onde foram regadas, manualmente, e observado, diariamente, o desenvolvimento das plântulas, descrevendo todas as características 
da morfologia externa. A germinação iniciou no $17^{\circ}$ dia após a semeadura, com a emissão da radícula. O início da emissão dos cotilédones deu-se no $19^{\circ}$ dia, com tegumento ainda persistente no ápice. No $25^{\circ}$ dia houve a exposição total dos cotilédones, foliáceos, de coloração verde. Desta forma, a germinação foi classificada como epígea fanerocotiledonar. Os primeiros eófilos surgiram 35 dias após a semeadura, apresentando-se simples, pubescentes, bordo liso, peciolados e com filotaxia oposta. A espécie expressou características semelhantes ao indivíduo adulto, porém com um leve polimorfismo, o que impossibilitou a identificação até o estádio de plântula.

Palavras-Chave: Cotilédone, germinação, plântula.

\section{Introdução}

A família Melastomataceae possui, em média, 5.000 espécies e 170 gêneros, com distribuição em regiões tropicais e subtropicais (Almeda et al., 2020). No Brasil, são encontrados, aproximadamente, 68 gêneros (Goldenberg et al., 2012) e 1.312 espécies, é a quinta maior família entre as angiospermas, no qual Miconia Ruiz \& Pav., Leandra Raddi e Tibouchina Aubl. foram os maiores gêneros com relação ao número de espécies e alto grau de endemismo (BFG, 2015).

No Brasil, o gênero Miconia está representado por, aproximadamente, 282 espécies (BFG, 2015), caracterizadas por frutos pequenos, carnosos, de polpa adocicada, com numerosas sementes pequenas e arredondados, sendo majoritariamente consumidos por aves (Maruyama et al., 2007). Entre as espécies, a Miconia prasina (Sw.) DC. pode ser considerada como pioneira, e é encontrada, tanto como componente do sub-bosque de florestas, como em áreas de florestas secundárias, clareiras naturais e em bordas de florestas, onde tem ocorrência mais abundante (Antonini \& Nunes-Freitas, 2004). Segundo estes autores, os indivíduos pertencentes ao gênero produzem muitas sementes e, em solos de ambientes degradados, o estabelecimento das suas plântulas pode ocorrer rapidamente. Portanto, é uma espécie com um papel fundamental para o processo de sucessão ecológica. No entanto, sua identificação em campo requer cuidados, pois as espécies pertencentes ao gênero Miconia apresentam uma grande similaridade entre si (Chagas, 2012; Silva, 2020), o que também ocorre em outros gêneros e famílias de espécies florestais, podendo citar a família Fabaceae, que apresenta similaridade entre gêneros e dentro do próprio gênero (Battilani, Santiago \& Dias, 2011).

A grande similaridade entre as espécies pode ser um problema na sua identificação, sendo um fator limitante em estudos de fenologia e comportamento de uma espécie dentro de uma comunidade (Kuniyoshi, 1983). Problemas na identificação ocorrem, principalmente, nas fases de plântula e muda, embora sejam fases críticas, quando acontece maior mortalidade, é também nessas fases que as espécies podem desenvolver características morfológicas adaptativas capazes de facilitar seu estabelecimento no ambiente, bem como desenvolver algumas estruturas que possam diferenciá-las de outras espécies do mesmo gênero (Garwood, 2009; Melo et al., 2004; Ferreira \& Barretto, 2015). Desta forma, demonstra-se a importância dos estudos morfológicos de frutos, sementes e plântulas como instrumento de suporte na identificação de espécies florestais (Paula, Nogueira \& Angelo, 2016).

Pesquisas envolvendo a análise morfológica podem ser utilizadas para diversos fins, podendo citar Barroso et al. (2004), que estudaram e descreveram as características da morfologia de sementes, frutos e plântulas de famílias e gêneros de dicotiledôneas. Estudos de Amorim et al. (2006) relataram a importância destes estudos nas análises laboratoriais, na identificação de espécies em viveiros e no reconhecimento da planta em campo.

Os estudos sobre a morfologia externa de plântulas fornecem subsídios para estudos sobre regeneração e sucessão natural, devido a dificuldade para identificação destas espécies regenerantes nas fases jovens, por apresentarem heterofilia ou outro tipo de modificação estrutural. Sendo assim, torna-se necessário ter uma atenção de como será feita a identificação destas espécies, com precisão, para poder contribuir com estudos sobre regeneração natural (Ferreira \& Barretto, 2015). Além disso, os estudos subsidiam uma interpretação correta em laboratórios de análise de sementes, como, por exemplo, podem auxiliar nos testes de germinação e na definição das estruturas essenciais das plântulas (Andrade et al., 2003; Lobo et al., 2014).

O processo de germinação se caracteriza como uma fase importante para as espécies vegetais, implicando diretamente no ciclo de vida das plantas (Cosmo et al., 2017). Para este processo, considera-se, envolvendo a tecnologia de sementes florestais, a emergência e o completo desenvolvimento das estruturas essenciais do embrião, evidenciando o potencial, sob condições favoráveis de campo, para produzir uma planta normal (Brasil, 2009). Esta fase é afetada por diversos fatores, entre elas estão o tipo de substrato, a luminosidade, a temperatura e a umidade; a influência destes fatores tem 
relevância ecológica e tecnológica, pois é a base para entender como as espécies nativas se propagam e como as comunidades vegetais se comportam no ambiente, sendo um fator chave para entender a regeneração natural (Cosmo et al., 2017).

O tipo de germinação e o estádio de desenvolvimento pode ocorrer de diferentes formas, podendo caracterizar-se por uma exposição dos cotilédones, livres do tegumento da semente, ou pode ocorrer o contrário, os cotilédones são mantidos, envolvidos pelo tegumento seminal, sendo denominados, respectivamente, de fanerocotiledonar e criptocotiledonar (Souza, 2003).

No geral, os termos fanerocotiledonar e criptocotiledonar se referem às características morfológicas da plântula. Contudo, o termo fanerocotiledonar está associado ao caráter epígeo, referindo-se ao desenvolvimento acima do nível do solo e o termo criptocotiledonar ao hipógeo. Esses termos têm uma certa equivalência, contudo, a relação não é obrigatória, podendo haver casos em que as plântulas têm um desenvolvimento em que elas são elevadas acima do solo e os cotilédones da semente continuam envoltos pelo tegumento, sendo assim, a germinação é epígea e criptocotiledonar (Beltrati \& Paoli, 2006).

Os diferentes tipos de germinação, associados com as diferenças morfológicas dos cotilédones, foliáceos fotossintetizantes ou de reserva das plântulas, podem resultar em distintas estratégias para competição, aquisição de recursos, defesa, sobrevivência e estabelecimento da planta em condições naturais (Cosmo et al., 2017; Silva, 2020).

Tendo em vista a importância deste tema, o estudo objetivou descrever a morfologia externa de Miconia prasina, em estádio inicial de desenvolvimento, visando identificar caracteres singulares da espécie que possam vir a ser utilizados para auxiliar na identificação e diferenciação entre espécies.

\section{Material e Métodos}

Os frutos de Miconia prasina foram coletados com auxílio de coletores instalados para avaliação da chuva de sementes em um remanescente de Floresta Ombrófila Densa das Terras Baixas (IBGE, 2012; Silva et al., 2018). O remanescente, conhecido como Mata do Camurim, possui área total de 243,40 hectares, está localizado no Engenho Camurim, em uma área de propriedade da Usina Petribú S/A., em São Lourenço da Mata, Pernambuco, Brasil.
O material retirado dos coletores, contendo frutos e sementes, foi acondicionado em sacos plásticos, identificado e levado para o Laboratório de Análise de Sementes Florestais (LASF), no Departamento de Ciência Florestal (DCFL) da Universidade Federal Rural de Pernambuco (UFRPE). O material foi triado, com posterior identificação dos frutos de Miconia prasina, os quais foram separados, beneficiados e as sementes foram lavadas com hipoclorito de sódio a $0,5 \%$, por cinco minutos, para desinfestação, em seguida lavados em água corrente.

Para a descrição das plântulas, as sementes foram colocadas em caixa de acrílico tipo gerbox $(11 \times 11 \times 3 \mathrm{~cm})$. Utilizou-se papel toalha da marca Absoluto (papel 100\% celulose virgem) como substrato, o qual foi devidamente esterilizado em estufa a $105^{\circ} \mathrm{C}\left( \pm 3^{\circ} \mathrm{C}\right)$ por duas horas. Os recipientes foram colocados em bancada em condições de laboratório com temperatura de $20^{\circ} \mathrm{C}$ e com umedecimento diário.

Após a germinação das sementes e crescimento inicial das plântulas, os indivíduos foram transplantados para recipientes de polietileno $(20 \times 15 \times 5 \mathrm{~cm})$ contendo solo comum e vermiculita. Em seguida foram levados e dispostos em bancada, na casa de vegetação do viveiro florestal-DCFL/UFRPE, onde foram regadas, manualmente, e o crescimento observado diariamente para verificar o desenvolvimento inicial das plântulas, caracterizando estruturas de interesse para a morfologia externa. As características acompanhadas foram: radícula, hipocótilo, cotilédones, epicótilo e classificação da germinação quanto ao tipo. Observou-se, também, toda característica adicional que pudesse contribuir com a identificação da espécie neste estádio inicial. Para a análise descritiva foram selecionados indivíduos sadios e, entre eles, escolheu-se apenas um para ilustração.

As terminologias utilizadas estão de acordo com os estudos desenvolvidos por Kuniyoshi (1983), Feliciano (1989) e Barroso et al. (2004).

\section{Resultados}

A germinação das sementes de Miconia prasina iniciou a partir do $17^{\circ}$ (décimo sétimo) dia, com a protrusão da radícula, fina, de coloração branca e cônica (Figura $1 \mathrm{AB}$ ), com hipocótilo fino, levemente quadrangular, glabro e de coloração verde-claro. O início da emissão dos cotilédones deu-se no $19^{\circ}$ dia, com a condução destes acima da superfície do solo e com tegumento ainda presente no ápice (Figura 1C-E). No $25^{\circ}$ dia ocorreu a exposição total dos 
cotilédones, de formato oval, com coloração verde, opostos, foliáceos, glabros e peciolados (Figura 1F), permitindo a classificação da plântula como do tipo epígea, fanerocotiledonar e com cotilédones foliáceos.

O primeiro eofilo surgiu aos 35 dias após a semeadura, simples, peciolados, opostos, bordo liso, de coloração verde, pubescentes, com pelos esbranquiçados (Figura 1G). O epicótilo, muito curto (ca. $1 \mathrm{~mm}$ ), com o surgimento dos eófilos que, posteriormente, vai se alongando, permanecendo reto, cilíndrico de coloração verde (Figura 1H).
Decorrido 170 dias após a semeadura, observou-se que o hipocótilo e o epicótilo da plântula apresentaram coloração verde-clara, glabros e cilíndricos, colo liso, cilíndrico, verdeclaro, com pouca diferenciação pela coloração (Figura 1I). Além disso, também se observou a presença de três pares de folhas, pubescentes, simples, opostas, cotilédones foliáceos persistentes, raiz principal de coloração esbranquiçada e com presença de raízes secundárias (Figura 1I).

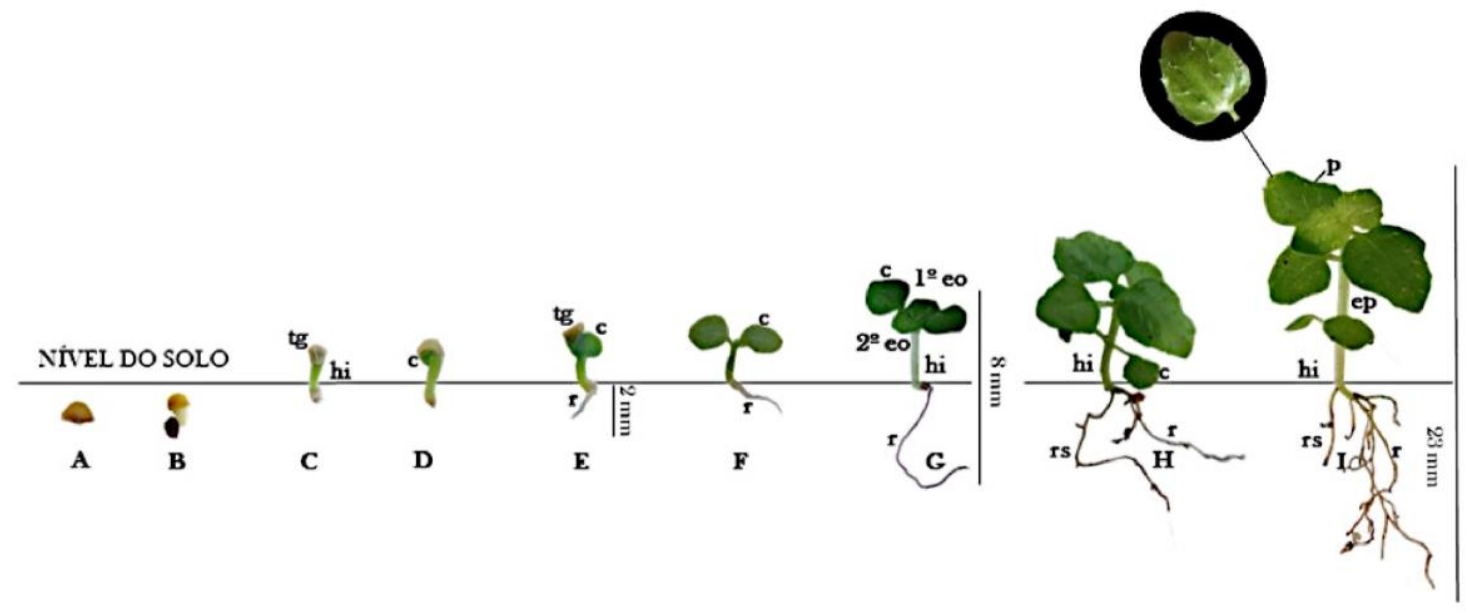

Figura 1. Aspectos morfológicos da germinação e desenvolvimento da plântula de Miconia prasina (Sw.) DC. em diferentes estádios de crescimento. $\mathrm{c}=$ cotilédone; $\mathrm{ep}=$ epicótilo; $\mathrm{g}=$ gema apical; hi $=$ hipocótilo; $\mathrm{p}$ $=$ pelos; $r d=$ radícula; $r=$ raiz; rs = raiz secundária. Fonte: Santana, Silva \& Marangon (2020).

\section{Discussão}

A germinação Miconia prasina é classificada como do tipo epígea fanerocotiledonar, sendo caracterizada como o tipo de germinação mais frequente e comum entre as espécies arbóreas do Brasil (Ressel et al., 2004; Lobo et al., 2014). Estudo desenvolvido por Silva (2020) apresentou a classificação de algumas espécies pertencentes à família Melastomataceae, principalmente do gênero Miconia spp.. Esse tipo de germinação está associado às plântulas provenientes de sementes muito pequenas (Ressel et al., 2004; Gogosz et al., 2015; Silva, 2020), o que indica um baixo teor de substâncias de reserva, justificando a presença de cotilédones fotossintéticos.

Mesmo tendo sementes e plântulas pequenas, as espécies pioneiras têm um rápido desenvolvimento, com plântulas dependentes da fotossíntese, o que é uma importante adaptação morfológica e funcional que resulta em uma resposta adaptativa para o estabelecimento das plântulas em ambientes com maior incidência de luz (Gogosz \& Boeger, 2019). Os autores destacam que a massa e a área dos cotilédones de espécies pioneiras também são menores, se comparada com espécies de estádios mais avançados na sucessão. Entretanto, mostram uma alta eficiência na alocação de tecidos fotossintéticos, sendo também uma estratégia para o estabelecimento em fases iniciais de sucessão.

Chaves et. al (2013), em estudo realizado com Miconia ligustroides (DC.) Naundim, observaram a presença de cotilédones fotossintéticos/foliáceos, germinação do tipo epígea fanerocotiledonar, corroborando o que foi observado, neste estudo, para Miconia prasina.

Silva (2020) observou que todas as espécies de Melastomataceae estudadas, apresentaram germinação do tipo epígea fanerocotiledonar e, de acordo com o grupo funcional, foram classificadas como pioneiras e secundárias iniciais, o que está correlacionado capacidade dessas espécies em ocupar áreas de clareiras e ambientes com maior incidência de luz.

Características das sementes e plântulas, como os cotilédones fotossintéticos associados ao tipo de germinação', fornecem um importante 
indicativo sobre o grupo sucessional ao qual a espécie pertence (Gogosz \& Boeger, 2019). Segundo Antonini \& Nunes-Freitas (2004), a Miconia prasina pertence ao grupo das pioneiras; os indivíduos deste grupo são mais dependentes da luz para germinar, sobreviver, crescer e se desenvolver (Gandolfi, 2000).

A expansão dos cotilédones foliáceos/fotossintéticos, na maioria das espécies, ocorre apenas após a germinação (Cosmo et al., 2017), pois estes são considerados uma adaptação para explorar aumentos na disponibilidade luminosa por meio de áreas abertas da floresta (Santos et al., 2015).

Em contrapartida, os cotilédones de reserva são considerados uma adaptação que confere às plântulas em ambientes sombreados, um maior tempo de sobrevivência, pois eles fornecem uma reserva nutricional capaz de conferir a energia necessária até o surgimento de condições favoráveis. Além disso, possuem a capacidade de germinar em maiores profundidades (Santos et al., 2015), existindo, assim, a possibilidade de fazer uma classificação das espécies com relação ao grupo funcional ao qual elas pertencem.

Em espécies de estágios sucessionais mais avançados, as sementes são maiores, com maior quantidade de tecido de reserva, do qual as mudas dependem. Além disso, o desenvolvimento é mais lento, demorando mais para expor os cotilédones; neste estádio existe a predominância de espécies com frutos carnosos, de dispersão zoocórica, com poucas sementes (Gogosz \& Boeger, 2019).

Plântulas com desenvolvimento epígeo, fanerocotiledonar, com cotilédones foliáceos, possuem rápido estabelecimento após a germinação, pois, logo no início do desenvolvimento, além dos eófilos, os cotilédones também permitem a produção fotossintética para o crescimento das plântulas (Gogosz et al., 2015; Cosmo et al., 2017).

As plântulas de espécies ocorrentes em florestas tropicais podem exibir uma grande diversidade morfológica para diferentes grupos taxonômicos, principalmente com variações no arranjo, na altura e na forma das folhas, podendo ter alteração dos cotilédones entre e dentro dos táxons (Lopes et al., 2012).

A presença de caracteres relevantes para a identificação das plântulas pode ser revelada por meio de estudos sobre a morfologia de espécies em fase de juvenil, pois essas características podem não permanecer evidentes em estádios mais avançados de desenvolvimento (Amorim et al., 2006). O conhecimento de estruturas transitórias permite ampliar a quantidade de informações sobre a plântula de determinada espécie, no decorrer do seu desenvolvimento e, com isso, ter caracterizações mais detalhadas das espécies florestais (Gurgel et al., 2012), uma vez que a variabilidade entre as espécies é explicada, principalmente, pelo tamanho da muda, com investimento em tecido para interceptação de luz e alocação de recursos (Gogosz \& Boeger, 2019).

É importante ressaltar que essa mudança representa apenas uma característica transitória no ciclo de vida da espécie, podendo se expressar na textura, diferenciação foliar, entre outras formas (Alves et al., 2013).

Em Miconia prasina, caracteres específicos observados na folha do indivíduo adulto não foram observados na fase de plântula, caracterizando um leve polimorfismo, pois não houve variações no tipo de folha e sim na forma da própria folha (Ferri, 1978).

Espécies da família Melastomataceae, principalmente aquelas pertencentes ao gênero Miconia, possuem uma similaridade acentuada, dificultando sua diferenciação em fases iniciais de desenvolvimento (Silva, 2020). As espécies, quando na fase adulta, apresentam folhas simples, pubescentes, com nervação trinervada e filotaxia oposta. Vale ressaltar que, na fase adulta, essas espécies podem apresentar caracteres específicos que facilitam essa diferenciação (Chagas, 2012).

A morfologia de plântulas fez-se necessária e auxiliou a identificação de diferentes espécies com base nos caracteres intrínsecos a elas, que foram expressos durante o desenvolvimento, seja baseado no tipo de germinação ou na presença de estruturas particulares inerentes a elas (Amorim et al., 2006; Baretto \& Ferreira, 2011; Ferreira \& Barretto, 2015).

Observando a importância e as informações que estudos sobre caracterização da morfologia de plântulas, Alves et al. (2013) ressaltaram que a realização de outros estudos com a mesma temática é importante para a ampliação das informações e dados, além de possibilitar a descoberta de caracteres taxonômicos com relativa importância informativa, auxiliando os estudos com enfoque ecológico, para os quais a correta identificação das plântulas seja necessária.

\section{Conclusão}

A Miconia prasina apresentou germinação do tipo epígea fanerocotiledonar, com cotilédones foliáceos/fotosintetizantes. Apresentou folhas simples, pubescentes, trinervadas e filotaxia oposta, características mantidas no indivíduo adulto. Devido à 
semelhança dos indivíduos pertencentes a esse gênero, não foi possível fazer a identificação desta espécie até a fase plântula, sendo necessário avaliar o desenvolvimento até fases mais avançadas. Até o momento da avaliação não foram observados caracteres confiáveis para garantir a distinção e a diferenciação entre as espécies.

\section{Agradecimentos}

Os autores agradecem ao Conselho Nacional de Desenvolvimento Científico e Tecnológico (CNPq) e a Universidade Federal Rural de Pernambuco (UFRPE), pela concessão da bolsa e participação do Programa Institucional de Bolsas de Iniciação Cientifica (PIBIC) da primeira autora e à Coordenação de Aperfeiçoamento de Pessoal de Nível Superior (Capes) pela concessão da bolsa de mestrado da segunda autora, possibilitando a execução deste estudo.

\section{Referências}

Almeda, F.; Goldenberg, R.; Michelangeli, F. A.; Cifuentes, H. M.; Renner, S. S.; Stone, D.; Ulloa, C. U.; Triebel, D. 2020. Melastomataceae.Net. A Site with Information on the Biodiversity of Melastomataceae. Disponível em: http://www.melastomataceae.net/.

Alves, M. C. J. L.; Lima, P. B.; Lima, L. F.; Zickel, C. S. 2013. Descrição morfológica para identificação das plântulas de nove espécies lenhosas de uma floresta de restinga. Revista Biota Neotropica, 13, 3, 374-383.

Amorim, I. L.; Ferreira, R. A.; Davide, A. C.; Chaves, M. M. F. 2006. Aspectos morfológicos de plântulas e mudas de trema. Revista Brasileira de Sementes, 28, 1, 86-91.

Andrade, A. C. S.; Cunha, R.; Souza, A. F.; Reis, R. B.; Almeida, K. J. 2003. Physiological and morphological aspects of seed viability of a neotropical savannah tree, Eugenia dysenterica DC. Seed Science and Technology, 31, 1, 125-137.

Antonini, R. D.; Nunes-Freitas, A. F. 2004. Estrutura populacional e distribuição espacial de Miconia prasina D.C. (Melastomataceae) em duas áreas de Floresta Atlântica na Ilha Grande, RJ, Sudeste do Brasil. Acta Botanica Brasilica, 18, 3, 671676.

Barretto, S. S. B; Ferreira, R. A. 2011. Aspectos morfológicos de frutos, sementes, plântulas e mudas de Leguminosae Mimosoideae: Anadenanthera colubrina (Vellozo) Brenan e Enterolobium contortisiliquum (Vellozo) Morong. Revista Brasileira de Sementes, 33, 2, 223-232.

Barroso, G. M; Amorim, M. P; Peixoto, A. L; Ichaso, C. L. F. 2004. Frutos e sementes: Morfologia aplicada à sistemática de dicotiledôneas. Viçosa: UFV.

Battilani, J. L; Santiago, E. F; Dias, E. S. 2011. Morfologia de frutos, sementes, plântulas jovens de Guibourtia hymenifolia (Moric.) J. Leonard (Fabaceae). Revista Árvore, 35, 5, 1089-1098.

Beltrati, C. M.; Paoli, A. A. S. 2006. Semente. In: Appezzato-da-Glória, B.; CarmelloGuerreiro, S. M. Anatomia vegetal. 2. ed., Viçosa: Ed. UFV. pp. 399-424.

BFG - The Brazil Flora Group. 2015. Growing knowledge: an overview of seed plant diversity in Brazil. Revista Rodriguésia, 66, 4, 1085-1113.

Brasil. Ministério da Agricultura, Pecuária e Abastecimento. 2009. Regras para Análise de Sementes. Secretaria de Defesa Agropecuária. Brasília: Mapa/ACS.

Chagas, E. C. O. 2012. O Gênero Miconia Ruiz \& Pav. (Melastomataceae) na Floresta Atlântica do Nordeste Oriental. Dissertação de Mestrado), Universidade Federal de Pernambuco. Recife, Pernambuco, Brasil. $115 f$.

Chaves, I. S.; Alvarenga, A. A.; Dousseau S.; Souza, E. S.; Artur, M. A. S.; Lara, T. S. 2013. Morphological characterization of fruits, diaspores and germination of Miconia ligustroides (DC.) Naundim (Melastomataceae). Revista Acta Scientiarum, Biological Sciences, 35, 1, 9398.

Cosmo, N. L.; Gogosz, A. M.; Rego, S. S.; Nogueira, A. C.; Kuniyoshi, Y. S. 2017. Morfologia de fruto, semente e plântula, e germinação de sementes de Myrceugenia euosma (O. Berg) D. Legrand (Myrtaceae). Revista Floresta, 47, 4, 479-488.

Feliciano, A. L. P. 1989. Estudo da germinação de sementes e desenvolvimento da muda, acompanhado de descrições morfológicas de dez espécies arbóreas ocorrentes no semiárido nordestino. Dissertação de Mestrado, Universidade Federal de Viçosa. Viçosa, Minas Gerais, Brasil. 114p.

Ferreira, R. A.; Barretto, S. S. B. 2015. Caracterização morfológica de frutos, sementes, plântulas e mudas de pau-brasil (Caesalpinia echinata Lamarck). Revista Árvore, 39, 3, 505-512. 
Ferri, M. G.; Menezes, N. L.; MonteiroScanavacca, W. R. 1978. Glossário ilustrado de botânica. São Paulo: EBRATEC: Editora da Universidade de São Paulo.

Gandolfi, S. 2000. História natural de uma Floresta Estacional Semidecidual no município de Campinas (São Paulo, Brasil). Tese de Doutorado, Universidade Estadual de Campinas, Instituto de Biologia. Campinas, São Paulo, Brasil. 292p.

Garwwod, N. C. 2009. Seedlings of Barro Colorado Island and the neotropics. Cornell University Press, New York, NY, US.

Gogosz, A. M.; Boerger, M. R. T.; Cosmo, N. L.; Nogueira, A. C. 2015. Morfologia de diásporos e plântulas de espécies arbóreas da floresta com araucária, no Sul do Brasil. Revista Floresta, 45, 4, 819 - 832.

Gogosz, A. M.; Boeger, M. R. T. 2019. Functional morphology of subtropical tree seedlings in southern Brazil. Revista Rodriguésia, 70, 01-12.

Goldenberg, R.; Baumgratz, J. F. A.; Souza, M. L. D. R. 2012. Taxonomia de Melastomataceae no Brasil: retrospectiva, perspectivas e chave de identificação para os gêneros. Revista Rodriguésia, 63, 1, 145-161.

Gurgel, E. S. C.; Santos, J. U. M.; Lucas, F. C. A.; Bastos, M. N. C. 2012. Morfologia de plântulas de Leguminosae e o potencial sistemático. Revista Rodriguésia, 63, 1, 065073.

IBGE. 2012. Manual técnico da vegetação brasileira. 2. ed. ver. e ampl. Rio de Janeiro: IBGE (Série Manuais Técnicos em Geociências, 1), 271p.

Kuniyoshi, Y. S. 1983. Morfologia da semente e da germinação de 25 espécies arbóreas de uma floresta com araucária. Dissertação de Mestrado, Universidade Federal do Paraná. Curitiba, Paraná, Brasil. 233p.

Lopes, A.; Rosa-Osman, S. M.; Piedade, M. T. F. 2012. Caracterização morfológica das plântulas de cinco espécies arbóreas da Floresta Estacional Semidecidual, Brasil. Revista Floresta, 42, 1, 105-114.

Lobo, G. A.; Santana, D. G.; Salomão, A. N.; Rehbein, L. S.; Wielewicki, A. P. 2014. A technological approach to the morphofunctional classification of seedlings of 50 Brazilian forest species. Journal of Seed Science, 36, 1, 087-093.

Maruyama, P. K.; Alves-Silva, E.; Melo, C. 2007. Oferta qualitativa e quantitativa de frutos em espécies ornitocóricas do gênero Miconia (Melastomataceae). Revista Brasileira de Biociências, 5, 1, 672-674.

Melo, M. G. G.; Mendonça, M. S.; Mendes, A. M. S. 2004. Análise morfológica de sementes, germinação e plântulas de jatobá (Hymenaea intermedia Ducke var. adenotricha (Ducke) Lee \& Lang.) (LeguminosaeCaesalpinioideae). Acta Amazonica, 34, 1, 9-14.

Paula, S. R. P.; Nogueira, A. C.; Angelo, A. C. 2016. Caracterização morfológica do fruto, semente, fases da germinação e plântula de Ocotea paranaenses. Revista de Ciências Agroveterinárias, 15, 2, 103-108.

Ressel, K.; Guilherme, F. A. G.; Schiavini, I. 2004. Ecologia morfofuncional de plântulas de espécies arbóreas da Estação Ecológica do Panga, Uberlândia, Minas Gerais. Revista Brasileira de Botânica, 27, 2, 311-323.

Santos, M. A.; Braga, L.F.; Rondon Neto, R. M.; Sorato, A. M. C. 2015. Aspectos morfológicos e fisiológicos da germinação e morfometria de frutos e sementes de Swartzia recurva Poep. (Fabaceae). Revista Ciência e Natura, 37, 4, 34-54.

Silva, J. P. G. 2020. Regeneração natural e morfologia de sementes e plântulas de espécies arbóreas em remanescente de Floresta Tropical Úmida, Pernambuco, Brasil. Tese de Doutorado, Universidade Federal Rural de Pernambuco. Recife, Pernambuco, Brasil. 153f.

Silva, J. P. G.; Marangon, L. C.; Feliciano, A. L. P.; Ferreira, R. L. C. 2018. Chuva de sementes e estabelecimento de plântulas em Floresta Tropical na região nordeste do Brasil. Ciência Florestal, 28, 4, 1478-1490.

Souza, L.A. 2003. Morfologia e anatomia vegetal: célula, tecidos, órgãos e plântula. Ponta Grossa: UEPG. 